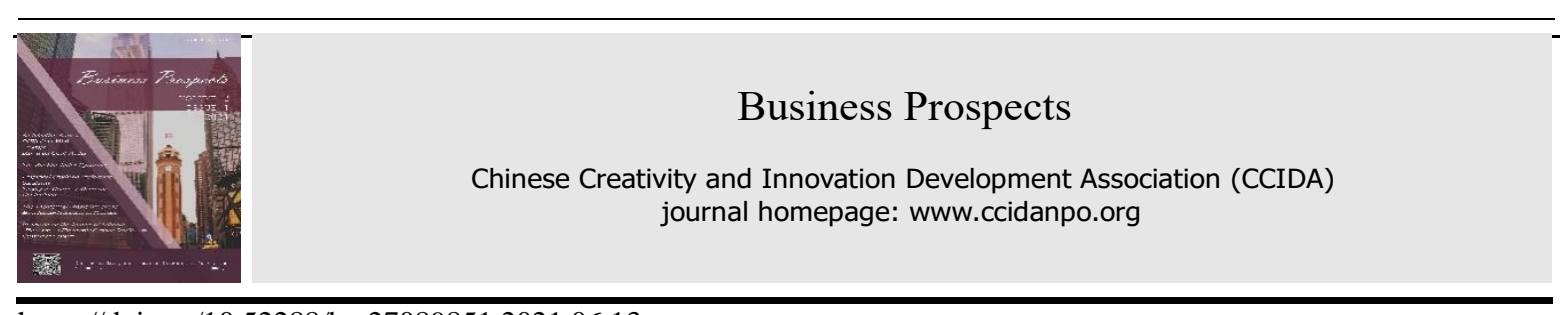

https://doi.org/10.52288/bp.27089851.2021.06.13

\title{
Deconstruction of Traditional "Equivalence" in the Translation of Chinese Classics
}

\author{
Yong-Mei He ${ }^{1, *}$ \\ ${ }^{1}$ Lecturer of School of the English Language and Culture, Xiamen University Tan Kah Kee College \\ * Correspondence: umail172@qq.com
}

Received: 2021.04.22; Accepted: 2021.05.10; Published: 2021.06.01

\begin{abstract}
Most traditional translation theories advocated that translation should strive to achieve "equivalence" between the target text and the original text. Deconstructive translation theory points out that the purpose of translation is not to seek common ground, but to preserve differences. Therefore, translation should try to reflect the differences between languages. This paper is intended to combine deconstruction theory of translation with linguistic theory in the translation of Chinese Classics. It analyzes the problems in the traditional translation theory in the translation of Chinese Classics from the perspective of seeking "equivalence" and tries to give some possible solution to the problems.
\end{abstract}

Keywords: Deconstruction; Equivalence; Chinese Classics

\section{Theory of Deconstruction School}

The Deconstructionist alternative arose primarily in France in the late 1960s during a time of a social and political upheaval. Derrida is always regarded as the father of deconstruction, who gave the lecture entitled "Structure, Sign and Play in the Discourse of Human Sciences" in Hopkins University in 1966, undraping the prelude of deconstruction. It produces profound influence in the later modern society. Now deconstruction is a strategy of analysis, which has been applied to literature, linguistics, philosophy, law, and architecture (Zima, 2002).

Derrida deconstructed the basis of the western philosophy. Aristotle wrote, "Spoken words are the symbols of mental experience and written words are the symbols of spoken words" (Derrida, 1968). Logos or speech, he implies, is closer to the signified, more present in the experience of signification. The written word, therefore, is always implicated as twice removed from "constitutive meaning"; it is simply a phonetic representation of what has been spoken to refer to what is.

As Derrida explains, however, this privilege of speech or logos, is, in fact, "the very origin of the notion of the 'signifier"' (Derrida, 1976). That is, within Aristotle's construction of meaning, speech and writing is the progress we have come to refer to as signification. But how then to deconstruct this dominant discourse? Derrida proposes that such a project begin with examination of the paradox of the immediacy of speech and the nevertheless privileged place of writing as "the first metaphor".

He thinks of reading and writing, the production or interpretation of signs, the text in general as fabric of signs, allows themselves to be confined within secondaries. They are preceded by a truth, or a meaning already constituted by and with the element of the logos. Even when the thing, the "referent," is not immediately related to the logos of a creator God where it began by being the spoken/thought sense, the signified has at any rate an immediate relationship with the logos in general (finite or infinite), and a mediated one with the signifier, that is, with the exteriority of writing. As such, writing is both distanced from "signification" and equated with "meaning" in the same stroke.

Further, and more important for the purposes of deconstruction literary critics, Derrida turned from Heidegger's sentimental question "How can we find traces of the remembrance of Being in the texts of the history of philosophy?" to the quasi-political questions "How can we subvert the intentions of texts which 
invoke metaphysical oppositions? How can we expose them as metaphysical?" He turned from Heidegger's preoccupation with the philosophical canon to the development of a technique, which could be applied to almost any text, past or contemporary, literary, or philosophical. This was the technique, which has come to be called "deconstruction."

The word "deconstruction" plays as small a role in Dread's writing as "Destruktion" played in Heidegger's. "Deconstructionism" was, initially, no more Dread's chosen label for his own thought than 'existentialism' was Heidegger's label for the doctrines of Being and Time. But, because Derrida was made famous (in Englishspeaking countries) not by his fellow-philosophers but by literary critics (who were looking for new ways of reading texts rather than for a new understanding of intellectual history), this label has (in those countries) become firmly attached to a school of which Derrida is, rather to his own surprise and bemusement, the leading figure. As used by members of this school, the term "deconstruction" refers in the first instance to the way in which the "accidental" features of a text can be seen as betraying, subverting its purportedly "essential" message.

\section{Aim of Translation of Chinese Classics}

The aim in translation determines the standards, principles, and devices of translation. Literary works in different styles have different aims in translation and ask for different standards and principles of translation (Bressler, 1994). The translation aim of the scientific and technique text is to explain new science and technology, to make people understood and to make the new technique be used in modern life. So, the translation versions of scientific and technological text are required to be objective, concise and accurate. The aims of literary translation are multiplied. Some translators put stress on literary study at the expense of introducing culture, while others stand on the opposite side. So, the aim of translation is the essential prerequisite of translation activity. Therefore, before we discuss the translation of Chinese Classics (TCC), we should talk about the aim/purpose of TCC.

In his book Translation as a Purposeful Activity, Nord (1997) divides the aims/purpose of translating into three groups:

(1) The essential purpose of translator

(2) Communicational purpose of target text

(3) The purpose of specified devices in translation

In order to fulfill the task of cultural communication, we discuss TCC from the following three aims/purposes:

(i) The essential purpose of a translator of TCC is to reflect the difference in cultures, so that it should transform the cultural information of source language (SL) text as much as possible.

(ii) The communicational purpose of target text in TCC is to introduce China ancient culture to western world, to let them know the origin of Chinese culture, to clear up the misunderstanding between different cultures, to reject the national centralism, to vindicate our national culture.

(iii) The purpose of using specified devices in TCC is to help the translator to transfer the cultural information better.

Like a boat should follow the direction indicated by the lighthouse, we should follow the light of the aim of cultural communication in TCC.

Next, we will discuss TCC in two aspects: standards and devices used in TCC.

\section{Deconstruction of Traditional Literary Translation Standard of "Equivalence"}

In the traditional sense of translation, form and meaning are the essential two elements of a text and form can be separated from meaning. Therefore, the target text can be faithful to the original one in the two aspects respectively. Nida is one of the representatives of those who support that being faithful to the form of the original text is expressly important. He proposes the theory of F-E/F-C theory. The definition of F-E translation given by Nida is "formal-equivalence (or F-E) translation is basically source-oriented; that is, it is designed to reveal as much as possible of the form and content of the original message" (Nida, 1964). Then he explains it concretely as "In doing so, an F-E translation attempts to reproduce several formal elements, including: (1) grammatical units; (2) consistency in word usage; and (3) meanings in terms of the source context. The reproduction of grammatical units may consist in: (a) translating nouns by nouns, verbs by verbs etc.; (b) 
keeping all phrases and sentence intact (i.e., not splitting up and readjusting the units); and (c) preserving all formal indicators e.g., marks of punctuation, paragraph breaks, and poetic indentation.” (Ibid, p165)

The following example is to illustrate what F-E translation means. If we translate “积土成山，风雨兴焉； 积水成渊, 蛟龙生焉; 积善成德, 而神明自得, 圣心备焉。” into English according to F-E theory, the translation will be “Accumulate earth to a hill, rain and wind will flourish; accumulate water to a chasm, dragons will be born; accumulate good to virtue, the divine will clarify itself, sage like mind will have."

In this translation we strictly abide F-E rules-not to split up and readjust the grammatical units; to translate nouns to nouns, verbs to verbs and to preserve all formal indicators, the marks of punctuation. But obviously that is not only wrong in the grammar but also obscure in meaning. This kind of translation violates the grammar of English as well as the meaning of original text. Of course, that is not we want.

The following charts make clear what is the essential requirement of F-E theory.

Nida supposes firstly, there are two equivalent language systems $\mathrm{X}$ and $\mathrm{Y}$ :

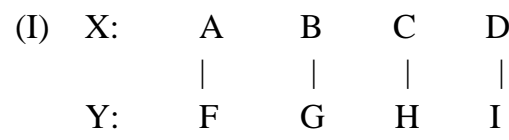

The grammatical elements A, B, C, D in system X are equivalent to the grammatical elements F, G, H, I in system Y. However, if there are not the equivalent grammatical elements (F, G, H, I) in system Y,

(II) X: $\quad \begin{array}{llll}\text { A } & \text { B } & \text { C } & \text { D } \\ & \mid & \mid & \mid\end{array}$

we should copy them into system Y as (III) shows

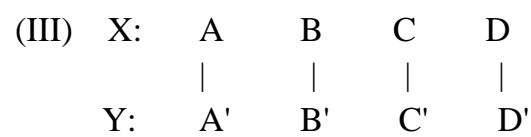

These charts show the basic idea of F-E translation, i.e., translating meaning of original text into TL and put it into the copied structure of the original text. If the two language systems, $\mathrm{X}$ and $\mathrm{Y}$, are entirely equivalent in grammar, the E-F translation is undoubtedly the best way of translation. But the problem is that, as we know, any language system is a patterned one. It has its own special grammar, for example, the subject-predicateobject structure is a common structure in English but in archaic Chinese, the subject and object are always placed after or before the predicate for instance, “积土成山”，“积水成渊”，“神明自得”.

The key point worth noticing is if there are no equivalent elements in system $\mathrm{X}$ and $\mathrm{Y}$, but if there is a relevant one, we should translate these elements in system $\mathrm{X}$ into their relevant elements in system $\mathrm{Y}$ as in

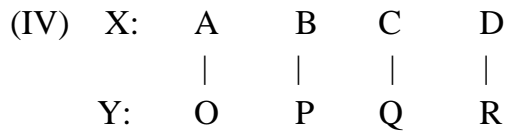

So “积土成山, 凤雨兴焉; 积水成渊, 蛟龙生焉; 积善成德, 而神明自得, 圣心备焉” may be translated into "When enough earth making up a high hill, rain and wind will flourish; when enough water filling in a gorge, dragons will be born in; when enough goodness accumulating in your heart, a divine clarity of intelligence will naturally acquire and a sage like mind will be fully realize."

The relevant grammatical elements of $\mathrm{A}, \mathrm{B}, \mathrm{C}, \mathrm{D}$, in system $\mathrm{X}$ are $\mathrm{O}, \mathrm{P}, \mathrm{Q}, \mathrm{R}$ in system $\mathrm{Y}$, and we name it relevant structure. In other words, the predicate-subject or the object-subject structure in archaic Chinese is the relevant structure of subject-predicate structure in English. Undoubtedly, we are to translate archaic Chinese sentences into their relevant structures in English.

The problem of precondition in F-E translation is that they think that form and meaning of a sentence can be separated and can find the equivalent ones in the target language system. But in the practical translation we will meet the difficulty that these two elements cannot find their equivalent elements in the target language system at the same time. As the meaning is always regarded as the center of a text, so, when we meet the contradiction between them, the form has to be sacrificed. The saying “得其意，忘其形” cried up by Chinese 
traditional theorists is the best proof of it. Traditional translation theorists always get into trouble with the contradiction between form and meaning.

But we think deconstruction may provide us some elicitation about this question.

In our traditional translation study, we are always unconsciously bonded by some binary opposite concepts: subjective-objective, original text-target text, meaning-form, and the author-translator. They are never equal. The second terms are always subordinate to the first ones. Therefore, when one of them should be sacrificed, it is the second ones of course. But the traditional theorists also want to give the second ones some equal rights (e.g. 一方面要力求其易懂，另一方面又要保持原作的风姿), so these two elements always struggle with each other in the process of translation. Thus, they can never reach agreements. Deconstructing binary opposite concepts is one of the characteristics of deconstructionism. Benjamin thinks that form and meaning are not two elements of a text, but entia, which cannot be separated. He believes that different languages are the fragments of a vessel (the vessel here is a metaphor of "pure language"18), which are to be glued together and must match one another in the smallest details, although they need not be similar. Translation is to find two fragments which maybe not resemble each other in the meaning, but "must lovingly and in the detail incorporate the original's mode of signification, thus making both the original and the translation recognizable as fragments of a greater language" (Schulte and Biguenet, 1992). If a language is one of fragments of a "vessel", its form and meaning are an entirety. When its form is changed, so is its meaning. The task of a translator is neither to change one of the fragments' forms into another one nor to find out the two similar pieces of fragments since that there are never two pieces of fragments are completely alike. His task is to find out how to connect them by anastomosis and how to glue them together.

If Chinese and English are the two pieces of fragments of the same vessel, can they be translated mutually since their forms are partially different?

It is true that parts of their forms and meanings are different, but it is not to say that they are totally different. Now that they are the two fragments of the same vessel, they certainly have same parts in form, since they can be connected by anastomosis and glued together.

Traditional linguistic theorists think that although the substance of language content is cut in different ways by different languages, people analyze the universal experience within a same general logic or psychological scope, whenever and wherever they are (Catford, 1965; Bhatnagar, 1993; Venuti, 2009). That is because in all the human languages, there are always some same human experiences of the same universe, and the cognitive scope in which these experiences are analyzed is shared by all the people. This opinion is unexpectedly like "pure language" proposed by Benjamin, which is an intention that no single language can attain by itself but "which realized only by totality of all language intentions supplementing each other" (Schulte and Biguenet, 1992). Languages have a kind of kinship relationship and all "suprahistorical kinship of languages rest in the intention underlying each language as a whole" (Ibid, 1992). While all individual elements of foreign language-words and sentences-are mutually exclusive, these languages supplement one another in their intentions. The word "bread" and "pain" intend the same object, but the modes of this intention are not the same. The mode of intention and the intention are called signified and signifier by Saussure. What the traditional theorists and deconstructionists want to show is, in fact, that human beings share some same universal experiences and cognitive scope, so languages are communicated and can be translated mutually. The kinship among archaic Chinese, modern Chinese and modern English is the same essential sentence structures. It is the foundation of literal translation in TCC.

\section{Standard for Translation of Chinese Classics}

As we have deconstructed the traditional standards of translation, there should be a new one, because if we lost standard in translation, translating will be a fish out of water, a ship without lighthouse. We will lose the existence basis of the target text and the direction of translating. Deconstructionists argue that the standard should not be the degree of similarity between the target text and the original one, but the degree of difference a target text can reflect.

Deconstructionists think that the reason why so many languages can exist in the world is the differences and supplemental relationships among them. A translator should not wipe them out, but should expose them as possible as he can. This idea, we think, is especially suitable to TCC.

The foremost reason that we follow it is that the aim of TCC is not only to make the reader in TL clear what the ancient works or the great thinkers mean, but also how these ideas are expressed. Otherwise, the target text will hinder the process of cultural communication. Form what has been discussed above, we may draw the 
conclusion that in order to help ancient Chinese culture be bright in the world again, we suggest to using a new standard and new device in TCC i.e., the target text should reflect difference between the SL and TL as possible as it can and neo-literal translation are to be used in TCC.

\section{References}

1. Bhatnagar, Y. C. (1993). Theory and Practice of Translation. Dehli: Ajanta Publications.

2. Bressler, C. E. (1994). Literary Criticism: An Introduction to Theory and Practice. New Jersey: Prentice-Hall, Inc.

3. Catford, J. C. (1965). A Linguistic Theory of Translation: An Essay in Applied Linguistics. London: Oxford University Press.

4. Derrida, J. (1968). Difference. (Tr.) Bass, A., 1982, Chicago: University of Chicago Press.

5. Derrida, J. (1976). Of Grammatology (Translated by Spivak, G.C.). Baltimore, MD: John Hopkins University Press.

6. Nida, E. A. (1964). Toward a Science of Translating. With Special Reference to Principles and Procedures Involved in Bible Translating. Leiden: Brill.

7. Nord, C. (1997). Translating as a Purposeful Activity: Functionalist Approaches Explained. Manchester: St. Jerome.

8. Schulte, R., \& Biguenet, J. (1992). Theories of Translation: An Anthology of Essays from Dryden to Derrida. Chicago: University of Chicago Press.

9. Venuti, L. (2009). Rethinking Translation: Discourse, Subjectivity, Ideology. London \& New York: Routledge.

10. Zima, P. V. (2002). Deconstruction and Critical Theory. Translated by Emig, R. London \& New York: Continuum.

(Editors: Loly Yan \& Amy Li) 